\title{
Hepatic gamma-glutamyltransferase activity in alcoholic fatty liver: comparison with other liver enzymes in man and rats
}

\author{
R TESCHKE, M NEUEFEIND, M NISHIMURA, AND G STROHMEYER
}

From the Medical Department D. University of Düsseldorf, Düsseldorf, FR Germany

SUMmaRY Compared with controls, patients with alcoholic fatty liver showed a significant increase of gamma-glutamyltransferase activity both in the liver and serum, whereas alkaline phosphatase activity was raised only in the liver but not in the serum. The activities of other enzymes such as aspartate aminotransferase, alanine aminotransferase and glutamate dehydrogenase remained virtually unchanged in the liver of patients with alcoholic fatty liver but were strikingly enhanced in the serum. The hepatic and serum alterations of enzymic activities observed in patients with alcoholic fatty liver could be reproduced in the rat model of alcoholic fatty liver only for gamma-glutamyltransferase but not for the other enzymes tested, substantiating evidence that the animal model may serve as an appropriate tool for studying interactions between alcohol and gamma-glutamyltransferase. The present experiments also indicate that the primary cause for increased serum gamma-glutamyltransferase activities associated with prolonged alcohol consumption is hepatic enzyme induction rather than liver cell injury.

Patients with alcoholic liver disease may exhibit increased serum activities of various enzymes including gamma-glutamyltransferase $(\mathrm{GGT}){ }^{1}$ alkaline phosphatase (ALP), ${ }^{2}$ aspartate aminotransferase (AST), ${ }^{13}$ alanine aminotransferase (ALT), ${ }^{3}$ and glutamate dehydrogenase $(\mathrm{GDH}){ }^{1}$ Rises in these enzyme activities are commonly found in the serum of patients with severe alcoholic liver disease, but they may be present already at early stages of the disease such as the fatty liver stage associated with alcohol abuse. In particular, striking rises of serum GGT are common already at the alcoholic fatty liver stage, and the determination of GGT is therefore now preferred to the transaminases for assessing early stages of liver disease due to alcohol abuse.

The pathogenesis of increased serum activities of various clinically used enzymes in alcoholic liver disease is poorly understood and might reflect enhanced leakage of enzymes out of the hepatocytes, hepatic enzyme induction or extrahepatic origin of enzymes because of alterations of other

Address for correspondence: Dr Rolf Teschke, Medical Department D of the University of Düsseldorf, Moorenstr. 5, 4000 Düsseldorf, FR Germany.

Received for publication 16 September 1982 tissues. The aim of the present investigation was therefore to study the relationship of commonly used hepatic enzymes in patients with alcoholic fatty liver by assessing the enzyme activities not only in the serum but also directly in the liver. Moreover, for comparison reasons, similar studies have been carried out in rats with alcoholic fatty liver due to prolonged ethanol intake in order to assess the validity of this commonly used experimental animal model regarding enzyme alterations observed under similar conditions in man.

\section{Methods}

PATIENTS

Nineteen alcoholics (seven women and 12 men, age $45 \pm 4$ years) with alcoholic fatty liver admitted to the Medical Department of the University of Düsseldorf were included in the study. The results of the clinical as well as laboratory examination had been suggestive of alcoholic liver disease, and blind liver biopsy or laparoscopy was indicated. After informed consent was obtained from each patient, liver specimens were obtained within one week after admission by blind liver biopsy using a Menghini 
needle or at laparoscopy. In general, $20-30 \mathrm{mg}$ of liver tissue were obtained, part of which was sent for routine histology. For the histological diagnosis of fatty liver the presence of fat droplets in more than $25 \%$ of the hepatocytes were required. The remaining liver specimen was immediately homogenised in $66 \mathrm{mM}$ phosphate buffer $(\mathrm{pH} \mathrm{7.4)}$ with a glass homogeniser, and the final homogenate containing $10 \mathrm{mg}$ of liver per millilitre was used for the subsequent enzyme assays. Blood was obtained by venepuncture on the same day of the liver biopsy, and after centrifugation the serum was used for enzyme assays.

The control group consisted of nine patients (five women and four men, $44 \pm 4$ years) with normal values of serum transaminases and gamma-glutamyltransferase and normal appearances of liver biopsy specimens, who underwent laparoscopy or laparotomy for diagnostic or therapeutic reasons. The alcohol consumption of this group was nil or negligible.

\section{EXPERIMENTAL STUDIES}

Sixteen female Sprague-Dawley rats were obtained from Zentralinstitut für Versuchstierzucht in Hannover (Federal Republic of Germany) and fed Altrumin laboratory chow and tap water ad libitum until they reached a body weight of 200-220 $\mathrm{g}$ which was achieved at an age of about 75 days. The animals were then housed in individual wired bottom cages and fed for six weeks with liquid diets in drinking tubes as the only source of food and water. The rats were pair-fed nutritionally adequate diets which contained either $36 \%$ of total calories as ethanol or additional carbohydrates on an isocaloric basis. ${ }^{4}$ At the end of the feeding procedure the animals were killed by decapitation, and blood was collected from the neck vessels for the determination of serum enzyme activities. Part of the liver was excised for histological examination by haematoxylin eosin staining, which revealed a fatty liver in the alcohol fed animals. The remaining liver was homogenised to be used for enzyme assays.

\section{BIOCHEMICAL DETERMINATIONS}

GGT activity was measured in liver homogenates and serum spectrophotometrically according to the method of Szasz. ${ }^{5}$ The activity of ALP was determined using the method of Hausamen et al, ${ }^{6}$ and for the measurement of AST activity the method of Bergmeyer and Bernt ${ }^{7}$ was followed. The activities of ALT and GDH were assayed by the method of Bergmeyer and Bernt ${ }^{8}$ and Schmidt, ${ }^{9}$ respectively. The determination of protein was performed according to the method of Lowry et al, ${ }^{10}$ using crystalline human albumin as standard.
STATISTICAL ANALYSIS

Each measurement was carried out in duplicate. The results are expressed as means ( \pm SD), and the significance of the differences was assessed by the Wilcoxon's test.

\section{Results}

GAMMA-GLUTAMYLTRANSFERASE

Compared with controls without biochemical and histological signs of liver disease, patients with the histological diagnosis of alcoholic fatty liver showed a striking rise of hepatic GGT activity (Table 1). The enhancement was $150 \% \quad(p<0.01)$ when expressed per gram of liver wet weight and $119 \%$ $(p<0.01)$ when calculated per gram of liver protein. Similarly, the hepatic GGT activity was significantly increased in rats with an alcoholic fatty liver after six weeks of alcohol intake when compared with animals fed the control diet (Table 2).

Patients with an alcoholic fatty liver exhibited a striking enhancement of serum GGT activity compared with controls (Table 1). There was also a significant rise of serum GGT activities in the experimental rat model of prolonged alcohol administration when compared with their respective controls pair-fed the control diet (Table 2). As in the hepatic enzyme activities, the basal and alcoholinduced serum levels of GGT activities were considerably lower in rats (Table 2) than in man (Table 1).

\section{ALKALINE PHOSPHATASE}

Alcoholic fatty liver in man was associated with a significant rise in hepatic ALP activity when compared with controls, and this alcohol mediated increase of hepatic ALP activity was not associated with any significant change of serum ALP activity (Table 1). Conversely, in rats with an alcoholic fatty liver a significant rise of serum ALP activity could be shown, whereas hepatic ALP activity remained virtually unchanged in comparison with their respective controls (Table 2). The basal levels of hepatic ALP activities were about one order of magnitude higher in man than in rats, whereas the corresponding serum values were in the same order of magnitude in both species (Table 1 and 2).

\section{ASPARTATE AMINOTRANSFERASE}

Compared with controls, hepatic AST activity remained virtually unchanged in patients with alcoholic fatty liver (Table 1) but was slightly increased in rats with alcoholic fatty liver when expressed per gram of liver wet weight or per 100 gram of body weight but not when calculated per gram of liver protein (Table 2). Serum AST 
Table 1 Enzyme activities in patients with alcoholic fatty liver

\begin{tabular}{lcc}
\hline Assay & Control & Alcoholic fatty liver \\
\hline Liver GGT (U/g wet weight) $\quad$ (U/g protein) & $1 \cdot 91 \pm 0 \cdot 62$ & $4 \cdot 78 \pm 1 \cdot 81 \dagger$ \\
Serum GGT (U/l serum) & $16 \cdot 4 \pm 6 \cdot 6$ & $35 \cdot 9 \pm 16 \cdot 1 \dagger$ \\
Liver ALP (U/g wet weight) $\quad 13 \cdot 7 \pm 5 \cdot 91$ & $195 \cdot 0 \pm 406 \cdot 7 \dagger$ \\
(U/g protein) & $3 \cdot 58 \pm 1 \cdot 54$ & $5 \cdot 22 \pm 2 \cdot 62^{*}$ \\
Serum ALP (U/l serum) & $30 \cdot 3 \pm 16 \cdot 8$ & $42 \cdot 2 \pm 24 \cdot 4^{*}$ \\
Liver AST (U/g wet weight) & $110 \cdot 7 \pm 72 \cdot 2$ & $124 \cdot 0 \pm 34 \cdot 9 \mathrm{NS}$ \\
(U/g protein) & $29 \cdot 2 \pm 11 \cdot 1$ & $35 \cdot 5 \pm 16 \cdot 5 \mathrm{NS}$ \\
Serum AST (U// serum) & $268 \cdot 0 \pm 138 \cdot 0$ & $257 \cdot 0 \pm 100 \cdot 3 \mathrm{NS}$ \\
Liver ALT (U/g wet weight) & $11 \cdot 1 \pm 4 \cdot 6$ & $34 \cdot 8 \pm 24 \cdot 6 \dagger$ \\
$\quad$ (U/g protein) & $19 \cdot 2 \pm 13 \cdot 8$ & $18 \cdot 5 \pm 37 \cdot 1 \mathrm{NS}$ \\
Serum ALT (U// serum) & $149 \cdot 0 \pm 78 \cdot 0$ & $137 \cdot 0 \pm 74 \cdot 0 \mathrm{NS}$ \\
Liver GDH (U/g wet weight) & $16 \cdot 6 \pm 8 \cdot 2$ & $30 \cdot 6 \pm 20 \cdot 2 \ddagger$ \\
$\quad$ (U/g protein) & $79 \cdot 2 \pm 30 \cdot 0$ & $80 \cdot 9 \pm 18 \cdot 3 \mathrm{NS}$ \\
Serum GDH (U/l serum) & $620 \cdot 0 \pm 207 \cdot 0$ & $591 \cdot 0 \pm 302 \cdot 4 \mathrm{NS}$ \\
Liver protein (mg/g wet weight) & $1 \cdot 92 \pm 2 \cdot 3$ & $9 \cdot 91 \pm 13 \cdot 2 \dagger$ \\
\hline
\end{tabular}

Enzyme activities of gamma-glutamyltransferase (GGT), alkaline phosphatase (ALP), aspartate aminotransferase (AST), alanine aminotransferase (ALT), and glutamate dehydrogenase (GDH) were determined in the liver and serum of patients with alcoholic fatty liver $(n=19)$ and in their respective controls without liver disease $(n=9)$. The results represent means \pm SD.

* $\mathrm{p}<0.05,+\mathrm{p}<0.01, \mp \mathrm{p}<0.001$.

Table 2 Enzyme activities in rats with alcoholic fatty liver

\begin{tabular}{ccc}
\hline & Control & Alcoholic fatty liver \\
\hline Livsay & $0 \cdot 07 \pm 0 \cdot 03$ & $0 \cdot 14 \pm 0 \cdot 06 \S$ \\
(U/g protein) & $0 \cdot 79 \pm 0 \cdot 19$ & $1 \cdot 19 \pm 0 \cdot 23 \ddagger$ \\
(U/100g bw) & $0 \cdot 34 \pm 0 \cdot 09$ & $0 \cdot 80 \pm 0 \cdot 28 \S$ \\
Serum GGT (U// serum) & $2 \cdot 19 \pm 0 \cdot 31$ & $4 \cdot 41 \pm 1 \cdot 64 \ddagger$ \\
Liver ALP (U/g wet weight) & $0 \cdot 40 \pm 0 \cdot 11$ & $0 \cdot 39 \pm 0 \cdot 08 \mathrm{NS}$ \\
(U/g protein) & $3 \cdot 66 \pm 0 \cdot 99$ & $3 \cdot 48 \pm 0 \cdot 59 \mathrm{NS}$ \\
(U/100g bw) & $1 \cdot 83 \pm 0 \cdot 60$ & $2 \cdot 25 \pm 0 \cdot 84 \mathrm{NS}$ \\
Serum ALP (U/l serum) & $161 \cdot 0 \pm 42 \cdot 4$ & $283 \cdot 0 \pm 67 \cdot 9 \ddagger$ \\
Liver AST (U/g wet weight) & $69 \cdot 9 \pm 6 \cdot 22$ & $96 \cdot 1 \pm 8 \cdot 2 \S$ \\
(U/g protein) & $729 \cdot 0 \pm 155 \cdot 6$ & $849 \cdot 0 \pm 87 \cdot 7 \mathrm{NS}$ \\
(U/100g bw) & $323 \cdot 6 \pm 40 \cdot 7$ & $498 \cdot 0 \pm 56 \cdot 5 \S$ \\
Serum AST (U/l serum) & $99 \cdot 0 \pm 14 \cdot 4$ & $108 \cdot 0 \pm 17 \cdot 3 \mathrm{NS}$ \\
Liver ALT (U/g wet weight) & $11 \cdot 1 \pm 2 \cdot 0$ & $20 \cdot 2 \pm 0 \cdot 49 \S$ \\
(U/g protein) & $121 \cdot 0 \pm 20 \cdot 1$ & $169 \cdot 0 \pm 26 \cdot 0 \S$ \\
(U/100g bw) & $55 \cdot 2 \pm 9 \cdot 2$ & $101 \cdot 2 \pm 12 \cdot 4 \S$ \\
Serum ALT (U// serum) & $25 \cdot 0 \pm 5 \cdot 9$ & $59 \cdot 2 \pm 9 \cdot 6 \S$ \\
Liver GDH (U/g wet weight) & $130 \cdot 0 \pm 19 \cdot 8$ & $168 \cdot 0 \pm 19 \cdot 8 \ddagger$ \\
(U/g protein) & $1221 \cdot 0 \pm 305 \cdot 5$ & $1431 \cdot 0 \pm 223 \cdot 4 \mathrm{NS}$ \\
(U/100g bw) & $558 \cdot 0 \pm 131 \cdot 4$ & $893 \cdot 0 \pm 182 \cdot 2 \S$ \\
Serum GDH (U// serum) & $3 \cdot 87 \pm 1 \cdot 44$ & $6 \cdot 80 \pm 2 \cdot 57 \dagger$ \\
Liver protein (mg/g wet weight) & $106 \cdot 1 \pm 23 \cdot 59$ & $117 \cdot 9 \pm 15 \cdot 74 \mathrm{NS}$ \\
(mg/100g bw) & $470 \cdot 57 \pm 97 \cdot 31$ & $594 \cdot 35 \pm 115 \cdot 1 \dagger$ \\
Liver weight (g) & $10 \cdot 96 \pm 1 \cdot 53$ & $11 \cdot 91 \pm 1 \cdot 55 \mathrm{NS}$ \\
(g/100g bw) & $4 \cdot 49 \pm 0 \cdot 64$ & $5 \cdot 04 \pm 0 \cdot 59 *$ \\
Body weight (g) & $244 \cdot 75 \pm 11 \cdot 85$ & $222 \cdot 38 \pm 45 \cdot 14 \mathrm{NS}$ \\
\hline
\end{tabular}

Enzyme activities of gamma-glutamyltranferase (GGT), alkaline phosphatase (ALP), aspartate aminotranferase (AST), alanine aminotransferase (ALT), and glutamate dehydrogenase (GDH) were determined in the liver and serum of rats with alcoholic fatty liver $(n=8)$ after feeding of a nutritionally adequate liquid alcohol diet for 6 weeks and in their pair-fed controls $(n=8)$. The results represent means $\pm S D$.

${ }^{*} \mathrm{p}<0.05, \dagger \mathrm{p}<0.025, \ddagger \mathrm{p}<0.01, \S \mathrm{p}<0.001$. 
activities were significantly enhanced in the fatty liver group only in man (Table 1) but not in rats (Table 2) when compared with their respective control groups. Basal AST activities were considerably higher in rats than in man, both in serum and liver (Table 1 and 2).

\section{ALANINE AMINOTRANSFERASE}

In comparison with controls, patients with alcoholic fatty liver failed to exhibit significant alterations of hepatic ALT activities (Table 1) whereas rats with an alcoholic fatty liver showed a pronounced increase of enzymic activity (Table 2). In the serum of both man (Table 1) and rats (Table 2) there was a significant rise of ALT activity in the alcoholic fatty liver group when compared with the corresponding control group. In addition, basal ALT activities of liver and serum were in the same order of magnitude for man and rats (Table 1 and 2).

\section{GLUTAMATE DEHYDROGENASE}

GDH activity was similar in the liver of patients with alcoholic fatty liver and of their corresponding controls, whether the data were given per gram of liver wet weight or per gram of liver protein (Table 1). Compared with controls, alcoholic fatty liver in rats was associated with a rise in hepatic GDH activity which was significant when expressed per gram of liver wet weight or per 100 gram of body weight but not when calculated per gram of liver protein (Table 2). In both man (Table 1) and rats (Table 2) with alcoholic fatty liver, however, there was a striking enhancement of serum GDH activities when compared with their respective control groups. Finally, basal values for hepatic and serum GDH activities were in the same order of magnitude both in man and rats (Table 1 and 2).

\section{ENZYME RATIO}

The serum enzyme ratio for AST/ALT in patients with alcoholic fatty liver was more than doubled compared with the respective controls, but the difference failed to achieve the level of statistical significance $(1 \cdot 64 \pm 1.57$ vs $0 \cdot 72 \pm 0 \cdot 24$; NS).

\section{Discussion}

The present study shows that patients with alcoholic fatty liver exhibit increased GGT activities not only in the serum but also in the liver when compared with their respective controls (Table 1). Conversely, enhanced hepatic ALP activities in this patient group are not associated with a concomitant rise of ALP activity in the serum. Moreover, the activities of other enzymes such as AST, ALT, and GDH remained virtually unchanged in the liver of patients with alcoholic fatty liver but were strikingly enhanced in the serum (Table 1). These data therefore show that GGT is a unique enzyme in the sense that its activity is augmented in both liver and serum of patients with alcoholic fatty liver, whereas ALP, AST, ALT, and GDH activities are increased either in the liver or in the serum.

There has been considerable debate concerning the mechanism of increased serum GGT activities owing to chronic alcohol consumption. ${ }^{11-14}$ Studies in experimental animals have shown that chronic alcohol consumption depresses hepatic GGT activities, suggesting that increased serum GGT activities might be because of an enhanced release of hepatic GGT into the bloodstream as a consequence of liver cell injury. ${ }^{14}$ This hypothesis, however, could not be substantiated in the present study showing an increased rather than decreased hepatic GGT activity after prolonged alcohol intake both in man (Table 1) and rats (Table 2), agreeing thereby with the interpretation of other reports. ${ }^{11} 15-23$ This study also clearly indicates that the commonly used rat model for alcohol feeding of DeCarli and Lieber ${ }^{4}$ is an appropriate tool for studying interactions between alcohol and GGT, as alterations of the GGT enzyme pattern in the serum and liver because of alcohol are similar in both species. Indeed, it has been speculated that enhanced activities of GGT observed after experimental alcohol feeding might exclusively be because of dietary imbalance with respect to carbohydrates rather than to alcohol itself, ${ }^{12}$ but this thesis was disproved by other studies. ${ }^{15} 18192223$

The observation of increased hepatic GGT activities due to prolonged alcohol intake both in man (Table 1) and experimental animals (Table 2) raises the question of the subcellular site of enhanced GGT activity in the liver cell. In experimental studies in rats, hepatic GGT activities have been found to be increased because of chronic ethanol consumption in microsomal fractions ${ }^{11} 1524$ as well as plasma membrane fractions of the hepatocytes, both free of as well as rich in bile canaliculi. ${ }^{16}{ }^{17}$ It is reasonable to assume that the hepatic induction of GGT activity after ethanol administration occurs primarily at the site of the endoplasmic reticulum. ${ }^{17}$ The enzyme could then be translocated to plasma membranes, possibly by means of the Golgi apparatus. The possibility cannot be ruled out, however, that part of the GGT activity recovered in the microsomal fraction is due to plasma membrane GGT, as contamination of microsomal fractions by plasma membranes during the course of subcellular fractionation is unavoidable. ${ }^{1617}$

Contrasting with the values obtained for GGT, 
ALP activities remained unchanged in the serum of patients with alcoholic fatty liver but were significantly enhanced in the liver (Table 1), whereas the reversed constellation was found in the experimental rat model with alcoholic fatty liver (Table 2). In addition, it is of particular interest that alcohol leads to a striking induction of ALP activity in the human liver, a condition not associated with an increased activity of the corresponding serum enzyme, suggesting that at the alcoholic fatty liver stage hepatic enzyme induction of ALP by itself is not sufficient to cause an increase of enzyme activity in the serum. As striking rises of serum ALP activities can be found in patients with severe stages of alcoholic liver disease, additional factors apart from hepatic enzyme induction have to be incriminated, and different isoenzymes may be also be involved.

Patients with alcoholic fatty liver failed to show significant alterations of hepatic AST, ALT, and GDH activities (Table 1). With respect to hepatic AST and ALT activities, similar results have been published in patients with fatty liver in the absence of alcohol abuse when compared with healthy controls. ${ }^{25}$ In patients with late stages of alcoholic liver disease, however, such as alcoholic hepatitis or cirrhosis, and associated striking increases of serum AST and ALT activities, a fall of hepatic AST and ALT activities was shown. ${ }^{25}$ It appears from these studies $^{25}$ as well as the present data (Table 1) that slight increases of serum AST and ALT activities are not necessarily associated with a significant change of hepatic enzyme activity, whereas this may not pertain to severe liver disease. ${ }^{25}{ }^{26}$ Under the latter conditions, hepatic AST and ALT may be released from the liver in amounts sufficient to cause a striking decrease of hepatic enzyme activity. It is also noteworthy that the data in man regarding AST, ALT and GDH activities (Table 1) could not be universally reproduced in the experimental rat model of chronic alcohol administration (Table 2).

Previous studies have shown that a AST/ALT ratio in the serum greater than two is highly suggestive for alcoholic hepatitis and cirrhosis. ${ }^{26}$ Conversely, the present study indicates that this statement may not be applicable for patients with alcoholic fatty liver. Indeed, in this patient group the mean value of AST/ALT ratio in the serum was only 1.64 , and dissociation from other forms of hepatobiliary diseases ${ }^{26}$ by the use of the serum enzyme ratio is therrefore not possible.

The authors are indebted to Mrs Helga Landmann for her excellent technical assistance. One of the authors (MN) is recipient of a fellowship from Heinrich-Hertz-Foundation Düsseldorf.

\section{References}

1 Worner TM, Lieber CS. Plasma glutamate dehydrogenase: clinical application in patients with alcoholic liver disease. Alcoholism: Clin Exp Res 1980; 4: 431-4.

2 Perrillo RP, Griffin R, DeSchryver-Kecskemeti K, et al. Alcoholic liver disease presenting with marked elevation of serum alkaline phosphatase. A combined clinical and pathological study. Dig Dis Sci 1978; 23: 1061-6.

3 Nishimura M, Hasumura Y, Takeuchi J. Effect of an intravenous infusion of ethanol on serum enzymes and lipids in patients with alcoholic liver disease. Gastroenterology 1980; 78: 691-5.

4 DeCarli LM, Lieber CS. Fatty liver in the rat after prolonged intake of ethanol with a nutritionally adequate new liquid diet. $J$ Nutr 1967; 91: 331-6.

5 Szasz G. A kinetic photometric method for serum $\gamma$-glutamyl transpeptidase. Clin Chem 1969; 15: 124-36.

6 Hausamen TU, Helger R, Rick W, et al. Optimal conditions for the determination of serum alkaline phosphatase by a new kinetic method. Clin Chim Acta 1967; 15: 241-5.

7 Bergmeyer HU, Bernt E. Glutamat-OxalacetatTransaminase. In: Bergmeyer HU, ed. Methoden der enzymatischen Analyse I. Weinheim: Verlag Chemie, 1970: 685-90.

8 Bergmeyer HU, Bernt E. Glutamat-PyruvatTransaminase. In: Bergmeyer HU, ed. Methoden der enzymatischen Analyse I. Weinheim: Verlag Chemie, 1970: 717-23.

9 Schmidt E. Glutamat-Dehydrogenase. In: Bergmeyer HU, ed. Methoden der enzymatischen Analyse I. Weinheim: Verlag Chemie, 1970: 607-13.

10 Lowry $\mathrm{OH}$, Rosebrough NJ, Farr AL, et al. Protein measurement with the folin phenol reagent. $J$ Biol Chem 1951; 193: 265-75.

11 Teschke R, Brand A, Strohmeyer G. Induction of hepatic microsomal gamma-glutamyltransferase activity following chronic alcohol consumption. Biochem Biophys Res Commun 1977; 75: 718-24.

12 Mørland J, Huseby NE, Sjøblom M, et al. Does chronic alcohol consumption really induce hepatic microsomal gamma-glutamyltransferase activity? Biochem Biophys Res Commun 1977; 77: 1060-6.

13 Mezey E. Alcohol consumption and $\gamma$-glutamyltransferase activity. Gastroenterology 1978; 74: 632-3.

14 Singer JS, Kaplan MM. Ethanol depresses rat liver gamma-glutamyl transpeptidase. Gastroenterology 1978; 74: A1095.

15 Ishii H, Yasuraoka S, Shigeta Y, et al. Hepatic and intestinal gamma-glutamyltranspeptidase activity: its activation by chronic ethanol administration. Life Sci 1978; 23: 1393-8.

16 Nishimura $M$, Stein $\mathrm{H}$, Berges $\mathrm{W}$, et al. Gammaglutamyltransferase activity of liver plasma membrane: Induction following chronic alcohol consumption. Biochem Biophys Res Commun 1981; 99: 142-8.

17 Nishimura M, Teschke R. Effect of chronic alcohol consumption on the activities of liver plasma 
membrane enzymes: gamma-glutamyltransferase, alkaline phosphatase and 5-nucleotidase. Biochem Pharmacol 1982; 31: 377-81.

18 Shaw S, Lieber CS. Mechanism of increased hepatic GGTP after chronic alcohol consumption: microsomal induction rather than dietary imbalance or liver necrosis. Gastroenterology 1979; 77: A41.

19 Gadeholt G, Aarbakke J, Dybing E, et al. Hepatic microsomal drug metabolism, $\gamma$-glutamyl transferase activity and in vivo antipyrine half-life in rats chronically fed an ethanol diet, a control diet and a chow diet. J Pharmacol Exp Ther 1980; 213: 196-203.

20 Ivanov E, Adjarov D, Etarska T, et al. Elevated liver gamma-glutamyl transferase in chronic alcoholics. Enzyme 1980; 25: 304-8.

21 Ideo G, Tempini S, Bellobuono A, et al. Biochemical and histochemical estimations of liver $\gamma$-glutamyltransferase activity in ethanol-fed rats. $J$ Clin Chem Clin Biochem 1980; 18: 237-9.
22 Petrides AS, Teschke R. Hepatic gamma-glutamyltransferase (GGT). Its increase in activity due to chronic alcohol consumption and its mechanism. Rev Franc Gastroenterologie 1980; 159: A22.

23 Teschke R, Petrides AS. Hepatic gamma-glutamyltransferase activity: its increase following chronic alcohol consumption and the role of carbohydrates. Biochem Pharmacol 1982; 31: 3751-6.

24 Ishii H, Okuno F, Ebihara Y, et al. Hepatic and intestinal gamma-glutamyltranspeptidase activity: Its enhancement after chronic ethanol administration and significance as a marker of alcoholic liver injury. Gastroenterology 1980; 79: A1132.

25 Matloff DS, Selinger MJ, Kaplan MM. Hepatic transaminase activity in alcoholic liver disease. Gastroenterology 1980; 78: 1389-92.

26 Cohen JA, Kaplan MM. The SGOT/SGPT ratio - an indicator of alcoholic liver disease. Dig Dis Sci 1979; 24: 835-8. 